\title{
MESO-SCALE SIMULATIONS OF LIGHTWEIGHT AGGREGATE CONCRETE UNDER IMPACT LOADING
}

\author{
Wang, S. R. ${ }^{* * *, \# ; ~ Z h a o, ~ J . ~ Q . ~ ; ~ W u, ~ X . ~ G . ~ ; ~ Y a n g, ~ J . ~ H . * ~ \& ~ L i u, ~ A . * ~}$ \\ * International Joint Research Laboratory of Henan Province for Underground Space Development and \\ Disaster Prevention, Henan Polytechnic University, Jiaozuo 454003, China \\ ${ }^{* *}$ State Collaborative Innovation Center of Coal Work Safety and Clean-Efficiency Utilization, \\ Henan Polytechnic University, Jiaozuo 454003, China \\ E-Mail: w_sr88@163.com $\left({ }^{\#}\right.$ Corresponding author $)$
}

\begin{abstract}
To reveal the damage evolution and energy dissipation characteristics of lightweight aggregate concrete (LWAC) under impact loading, some simulations of lightweight shale ceramsite concrete under high strain rate impact with a 3D meso-scale model were carried out. After the meso-scale model considering the randomness of the shape and distribution of lightweight aggregates being established and the material parameters of each component being determined by test results, the damage evolution and energy dissipation characteristics of the model under different strain rates were analysed. Results show that the damage evolution of LWAC can be divided into four stages from the perspective of energy. The large deformation and stress concentration firstly occur on the lightweight aggregates, which leads to the generation of micro-cracks. There is an upper limit of the strain energy density of the lightweight aggregate component. The energy absorption efficiency of the specimen first increases and then decreases with the increase of strain rates. The obtained conclusions can provide a reference for understanding the dynamic performances and damage mechanism of LWAC. (Received in January 2021, accepted in April 2021. This paper was with the authors 1 month for 1 revision.)
\end{abstract}

Key Words: Lightweight Aggregate Concrete, Strain Rate, Energy Dissipation, Simulation, Damage

\section{INTRODUCTION}

Lightweight aggregate concrete (LWAC) has been widely used in high-rise buildings, longspan bridges and fabricated structures due to its lightweight, heat insulation and environmentfriendly advantages [1].

Lightweight concrete structures will inevitably be affected by earthquakes, impacts, and blasts during service, while their mechanical properties under dynamic loads are different from that under static loads [2]. The split Hopkinson pressure bar (SHPB) test has been applied to study the dynamic characteristics of LWAC, but the influence of the lightweight aggregate on damage evolution and energy dissipation cannot be quantitatively measured by laboratory tests $[3,4]$. As a kind of heterogeneous material, the performances of LWAC depend on the properties of the lightweight aggregate [5]. Meso-scale simulations can quantitatively analyse the effects of meso-scope components of the concrete, thus it is considered to be the most effective method to study the damage mechanism of the concrete [6]. Besides, due to the limitation of the cost and test methods, it is hard to implement the tests of large engineering structure under dynamic loading, while meso-scale simulation can easily deal with these problems.

Therefore, it is of great scientific significance and engineering value to study the mechanical performances of LWAC under dynamic loading by establishing a 3D finite element model considering the random shape and distribution of aggregates.

\section{STATE OF THE ART}

The SHPB test is often employed to study the dynamic mechanical properties of concrete materials [7]. Bai et al. conducted SHPB tests on two types of lightweight concrete and they 
found that the peak stress of concrete under impact loading was related to strain rates and material density [8]. Dehdezi et al. added different content of rubber to ordinary concrete and studied the absorption energy under impact loading. The results showed that lightweight concrete had higher dissipation capacity than ordinary concrete [9]. Recently, the high speed camera had been developed to observe the failure process, but damage of concrete and the accompanying energy dissipation could not be described quantitatively [10]. Some scholars have studied this problem from a macro perspective through numerical simulation [11]. However, as a kind of composite material, the mechanical properties of LWAC are greatly affected by lightweight aggregates [12]. It is necessary to make a quantitative analysis on the contribution of energy absorption and consumption of the lightweight aggregate from the micro perspective. Therefore, the meso-numerical method of concrete has become an increasingly popular alternative method.

The meso-structure model of concrete is very important for evaluating its mesomechanical properties [13]. The concrete can be regarded as a two-phase composite structure composed of the aggregate and the mortar matrix. The modelling method of meso-scale can well simulate and predict the cracking behaviour of concrete [14]. Now, there are two main numerical methods to create the meso-scale model. One is the digital imaging method, which truly reflects the meso-structure of the specimen acquired by optical devices such as cameras, microscopes and X-ray computed tomography (XCT) [15]. The Monte Carlo method, the other one, constructs the meso-structure of concrete with statistical methods, which cost lower than the digital imaging method [16]. The simulation methods of creating concrete model mainly include continuous, discontinuous and continuous-discrete methods. The continuousdiscrete method includes extended finite element method (XFEM) and cohesive zone material (CZM) modelling method [17], which is a powerful tool to investigate the fracture failure in multiphase materials, but it has little application in dynamics simulation. The discontinuous method mainly includes discrete element method (DEM) and smoothed particle flow method (SPH) $[18,19]$. In addition, element-free Galerkin method (EFG) and cracking-particle method (EFG-P) have also been applied to the meso-simulation of concrete $[20,21]$. The discontinuous method and the continuous-discrete method are excellent in describing the cracking behaviour. But compared with the continuous method, the contact parameters of interfaces need to be set artificially, and the computational resources are much larger. Besides, many micro-mechanical models have been proposed to study the fracture process, such as lattice model, random particle model (RPM) and random aggregate model (RAM) [13, 22, 23]. Among them, RAM has higher computational efficiency, simpler parameterization process and the random shape of the aggregate can be considered [6]. Therefore, the 3D finite element model considering the random shape and distribution of aggregates is a preferred one to simulate the meso-structure of concrete.

Based on meso-scale modelling method, some scholars have studied the dynamic mechanical performances of ordinary concrete, rubber and coral aggregate concrete [24-26]. However, different from the concretes mentioned above, the aggregate in lightweight shale ceramsite concrete (LWSCC) are obtained by artificial calcination. Enamel surface, porous structure and the crystal formed at high temperature are the main contributors to the light weight and high strength [27]. Moreover, the ceramsite aggregate with water absorption/release characteristic on account of porous structure, could facilitate the hydration process, resulting in the densification of the microstructure [28]. Although the static and dynamic characteristics of LWSCC have been studied through experiments, the process and mechanism of damage have not been revealed $[3,4]$. Therefore, it is necessary to do mesoscale simulation research on LWSCC.

In this study, a 3D meso-scale model of LWSCC was established. The SHPB test simulations under different strain rates were carried out by using software LS-DYNA. By 
comparing with the experimental data, the reliability of the numerical model and the parameters of the Holmquist-Johnson-Cook (HJC) model were verified. The failure mode and damage evolution process of LWSCC under different strain rates were illustrated based on the model. The energy consumption characteristics of LWSCC and the role of the lightweight aggregate in energy dissipation were analysed quantitatively.

\section{METHODOLOGY}

\subsection{Sample preparation}

A LWSCC specimen is mainly made from cement, lightweight aggregates and fly ash. The Portland cement used in this study with grade of C42.5 was produced by Jiaozuo Cement Factory. The fly ash was produced by the Jiaozuo Power Plant. The lightweight aggregates were composed of shale ceramsite (particle size $5-15 \mathrm{~mm}$ ) and shale pottery (particle size 0-5 $\mathrm{mm}$ ). These parameters are shown in Table I. The water reducing agent was naphthalene series, the water reducing rate was $15 \%$, and the dosage was $1.6 \%$ of the quality of cementitious material. The mix proportions are given in Table II.

Table I: Physical and mechanical parameters of aggregates.

\begin{tabular}{|c|c|c|c|c|c|}
\hline Aggregate & $\begin{array}{c}\text { Bulk density } \\
\left(\mathrm{kg} / \mathrm{m}^{3}\right)\end{array}$ & $\begin{array}{c}\text { Diameter } \\
(\mathrm{mm})\end{array}$ & $\begin{array}{c}\text { Water absorption } \\
(\%)\end{array}$ & $\begin{array}{c}\text { Tube crushing } \\
\text { strength }(\mathrm{MPa})\end{array}$ & $\begin{array}{c}\text { Fineness } \\
\text { modulus }\end{array}$ \\
\hline Shale ceramsite & 650 & $5-15$ & 4 & 3.20 & - \\
\hline Shale pottery & 880 & $0-5$ & 12.5 & - & 3.15 \\
\hline
\end{tabular}

Table II: The mix proportions of LWSCC $\left(\mathrm{kg} / \mathrm{m}^{3}\right)$.

\begin{tabular}{|c|c|c|c|c|c|c|}
\hline Materials & Cement & Fly ash & Shale pottery & Shale ceramsite & Water reducer & Water \\
\hline Amount & 400 & 160 & 369.4 & 474.6 & 3.41 & 99 \\
\hline
\end{tabular}

The shale ceramsite needed to be pre-wetted for 24 hours before mixing. The aggregates were firstly added into a forced stirrer with $1 / 2$ of the water. Then the cement, the fly ash and the water reducer were put into the stirrer in turn for 2-min mixing. Finally, the remaining water were added and stirred for 2 minutes. The mixture was vibrated and shaped in moulds with the size of $150 \mathrm{~mm} \times 150 \mathrm{~mm} \times 300 \mathrm{~mm}$. After casting for 48 hours, the specimens were demoulded and cured in the standard curing room for 28 days. The cylinder specimens with the size of $\Phi 100 \mathrm{~mm} \times 50 \mathrm{~mm}$ were obtained by dissection and polishing.

\subsection{SHPB test method}

The SHPB test has been widely applied to study the mechanical properties of materials at high strain rates, which consists of loading devices, impact and compression components, and a data acquisition system. The impact and compression system includes bullet, incident and transmission bars made of steel with lengths of $0.8 \mathrm{~m}, 5.0 \mathrm{~m}$ and $3.0 \mathrm{~m}$, respectively.

The bullet could be accelerated to a certain high velocity by the sudden release of the high-pressure air and impacts the incident bar, which produces elastic strain wave at the end of the incident bar called incident pulse. While the incident pulse propagated and reached the specimen, part of the pulse reflected back to the incident bar called reflected pulse, and the rest passed through the specimen and got to the transmission bar called transmission pulse. After aligning the three waves, the superposition of incident wave and transmitted wave was 
in good agreement with reflected wave as shown in Fig. 1, which indicated that the loading process conforms to the stress uniformity assumption.

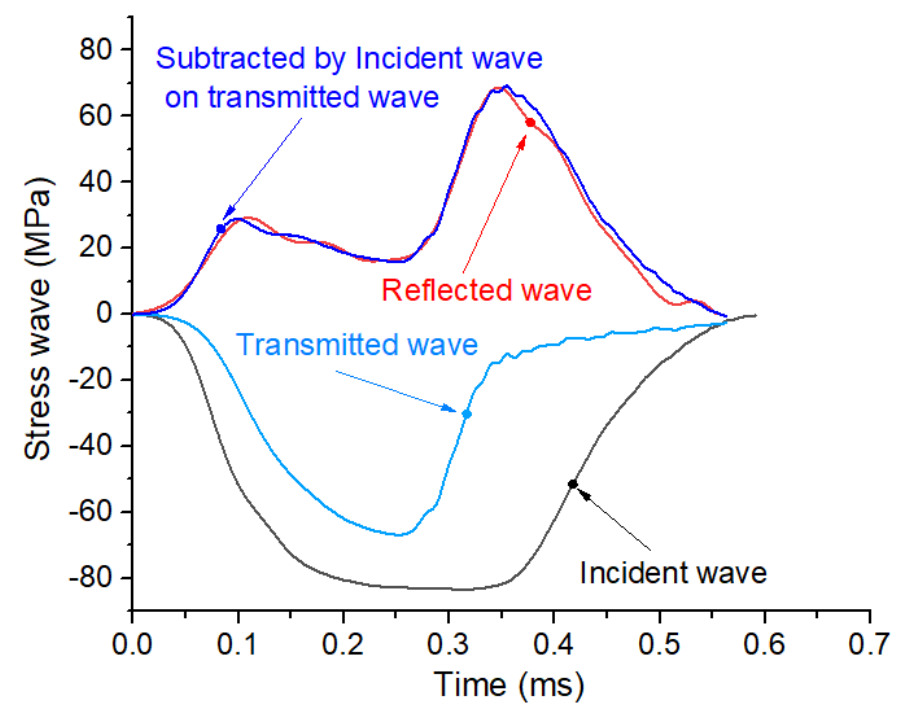

Figure 1: Stress balance diagram.

According to the hypothesis of stress uniformity, the stress, strain and the strain rate of the sample can be calculated as below:

$$
\begin{gathered}
\sigma_{\mathrm{S}}=\frac{E A_{0} \varepsilon_{\mathrm{T}}}{A_{\mathrm{S}}} \\
\dot{\varepsilon}_{\mathrm{S}}=\frac{2 C_{0}\left(\varepsilon_{\mathrm{I}}-\varepsilon_{\mathrm{T}}\right)}{L_{\mathrm{S}}} \\
\varepsilon_{\mathrm{S}}=\frac{2 C_{0}}{L_{\mathrm{S}}} \int_{0}^{t}\left(\varepsilon_{\mathrm{I}}-\varepsilon_{\mathrm{T}}\right) \mathrm{d} t
\end{gathered}
$$

\subsection{Meso-scale modelling of 3D random particles}

The LWSCC specimen was regarded as a composite of mortar and shale ceramsite aggregates with size of 5-15 mm. The aggregates whose size distribution conformed to fuller gradation curve were randomly distributed in the mortar. The algorithm for the generation of 3D convex solid particle model considering the random shapes was written in MATLAB. Using Monte Carlo method, the aggregates were randomly put into the spatial area in the order of particle size from large to small with identifying the intersection by the linear programming algorithm. The concrete geometric model is shown in Fig. 2 b. The geometric model of the specimen (Fig. 2 c) could be obtained by cutting the concrete geometric model into the actual size. Finally, the material identification algorithm and the mapping algorithm were successively used for the mesh generation to get the finite model (Fig. $2 \mathrm{~d}$ ). On the premise of fully characterizing the shape and size of aggregates, the element size was set as $0.625 \mathrm{~mm}$ in order to ensure the calculation efficiency.

As shown in Fig. 3, the finite models of SHPB test components were established including incident bar, transmission bar $(3.3 \mathrm{~m})$ and specimen $(50 \mathrm{~mm})$, whose diameters were all $100 \mathrm{~mm}$. Based on the experimental data, the stress wave was applied at the end of the incident bar. The stress monitoring points were set in the middle of the incident bar and the transmission bar, respectively. 


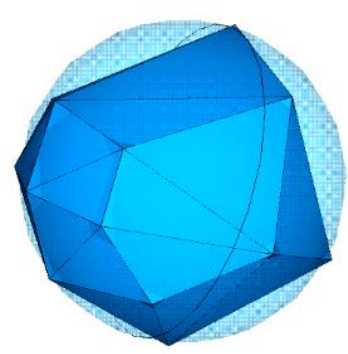

a)

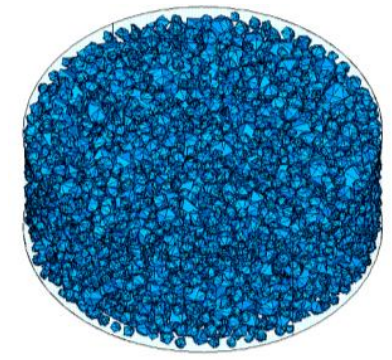

b)

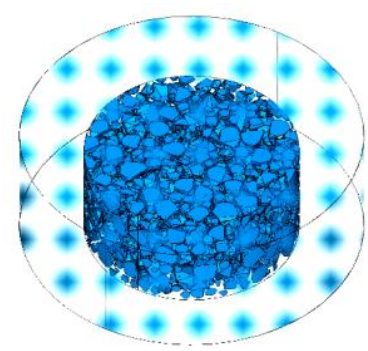

c)

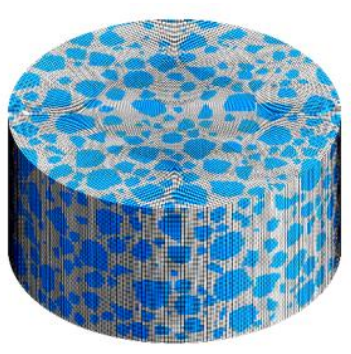

d)

Figure 2: Schematic view of numerical models: a) geometry model of a single aggregate, b) geometric mode, c) geometry model of a specimen, d) FEM model of concrete.

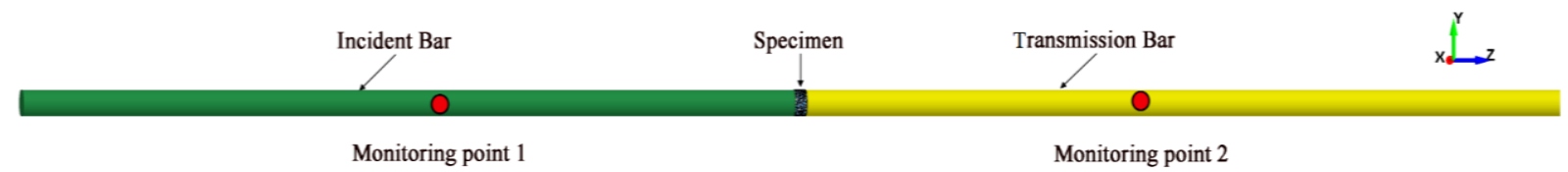

Figure 3: Split Hopkinson Pressure Bar (SHPB) test model.

\subsection{HJC model}

The material model of HJC has been developed to simulate material behaviours of the mortar, the aggregates in the numerical study under high strain rate loads. The model mainly includes yield surface equation, damage evolution equation and state equation as shown in Fig. 4 [25]. Among them, the yield surface equation is described by dimensionless equivalent stress, and the effects of material damage and strain rates are taken into consideration. The damage equation is described by the accumulation of equivalent plastic strain and plastic volumetric strain. And the state equation reflects the relationship between hydrostatic pressure and volumetric strain. The parameters were determined based on the LWSCC test results and a great deal of parametric tests. And the results are shown in Table III and Table IV.

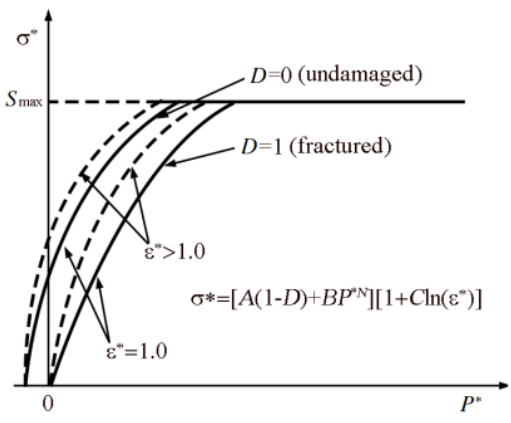

a)

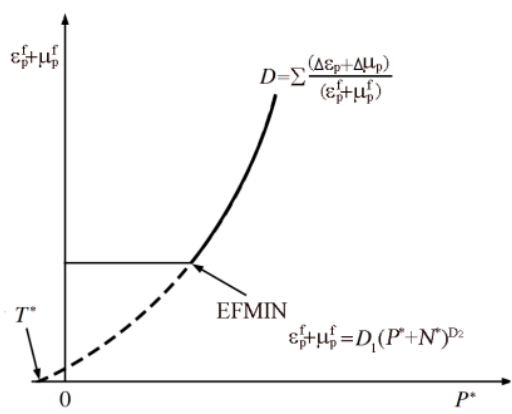

b)

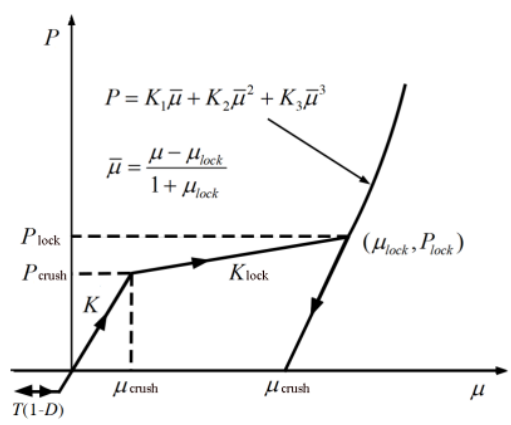

c)

Figure 4: HJC model: a) yield surface equation, b) damage evolution equation, c) state equation.

Table III: HJC constitutive model parameters of mortar matrix.

\begin{tabular}{|c|c|c|c|c|c|c|}
\hline $\boldsymbol{\rho}\left(\mathrm{kg} / \mathrm{m}^{3}\right)$ & $\boldsymbol{G}(\mathrm{GPa})$ & $\boldsymbol{A}$ & $\boldsymbol{B}$ & $\boldsymbol{N}$ & $\boldsymbol{C}$ & $\boldsymbol{f}_{\boldsymbol{c}}^{\prime}(\mathrm{MPa})$ \\
\hline 1580 & 1.50 & 0.30 & 1.80 & 0.84 & 0.01 & 38.0 \\
\hline $\boldsymbol{f}_{\boldsymbol{t}}(\mathrm{MPa})$ & $\mathbf{E F M I N}$ & $\mathbf{S M A X}$ & $\boldsymbol{P}_{\text {crush }}(\mathrm{MPa})$ & $\boldsymbol{\mu}_{\text {crush }}$ & $\boldsymbol{P}_{\text {lock }}(\mathrm{MPa})$ & $\boldsymbol{\mu}_{\text {lock }}$ \\
\hline 3.50 & 0.01 & 4.00 & 14.0 & 0.0004 & 240 & 0.10 \\
\hline $\boldsymbol{D}_{\mathbf{1}}$ & $\boldsymbol{D}_{\mathbf{2}}$ & $\boldsymbol{K}_{\mathbf{1}}(\mathrm{GPa})$ & $\boldsymbol{K}_{\mathbf{2}}(\mathrm{GPa})$ & $\boldsymbol{K}_{\mathbf{3}}(\mathrm{GPa})$ & $\boldsymbol{f}_{\text {s }}$ & $\mathbf{m x e p s}$ \\
\hline 0.01 & 1.00 & 20.0 & -100 & 500 & 0.003 & 0.10 \\
\hline
\end{tabular}


Table IV: HJC constitutive model parameters of aggregate.

\begin{tabular}{|c|c|c|c|c|c|c|}
\hline $\boldsymbol{\rho}\left(\mathrm{kg} / \mathrm{m}^{3}\right)$ & $\boldsymbol{G}(\mathrm{GPa})$ & $\boldsymbol{A}$ & $\boldsymbol{B}$ & $\boldsymbol{N}$ & $\boldsymbol{C}$ & $\boldsymbol{f}_{\boldsymbol{c}}^{\prime}(\mathrm{MPa})$ \\
\hline 800 & 6.40 & 0.30 & 1.80 & 0.84 & 0.044 & 18.5 \\
\hline $\boldsymbol{f}_{\boldsymbol{t}}(\mathrm{MPa})$ & $\mathbf{E F M I N}$ & $\mathbf{S M A X}$ & $\boldsymbol{P}_{\text {crush }}(\mathrm{MPa})$ & $\boldsymbol{\mu}_{\text {crush }}$ & $\boldsymbol{P}_{\text {lock }}(\mathrm{MPa})$ & $\boldsymbol{\mu}_{\text {lock }}$ \\
\hline 1.07 & 0.003 & 4.00 & 14.0 & 0.001 & 280 & 0.20 \\
\hline $\boldsymbol{D}_{\mathbf{1}}$ & $\boldsymbol{D}_{\mathbf{2}}$ & $\boldsymbol{K}_{\mathbf{1}}(\mathrm{GPa})$ & $\boldsymbol{K}_{\mathbf{2}}(\mathrm{GPa})$ & $\boldsymbol{K}_{\mathbf{3}}(\mathrm{GPa})$ & $\boldsymbol{f}_{\text {s }}$ & $\mathbf{m x e p s}$ \\
\hline 0.008 & 1.00 & 15.0 & -80 & 200 & 0.003 & 0.10 \\
\hline
\end{tabular}

\section{RESULTS AND DISCUSSION}

\subsection{Experimental results and model validation}

The failure modes of specimens under different impact air pressures $P$ obtained by laboratory tests and simulation tests are shown in Figs. 5 and 6 . No obvious failure occurred under the air pressure of $0.2 \mathrm{MPa}$. With the increasing of the $P$, the specimens gradually failed from the periphery to the centre. When the $P$ reached $0.5 \mathrm{MPa}$, the concrete specimen was completely destroyed and the aggregates cracked or crushed. The failure modes of the specimen in the test were consistent with the simulation results.

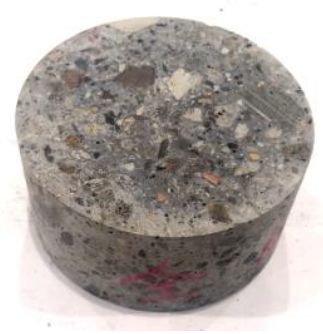

a)

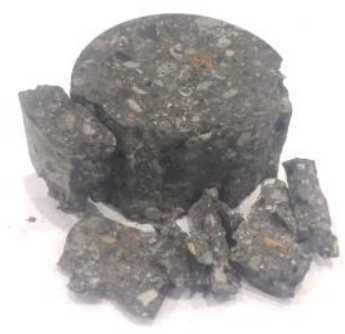

b)

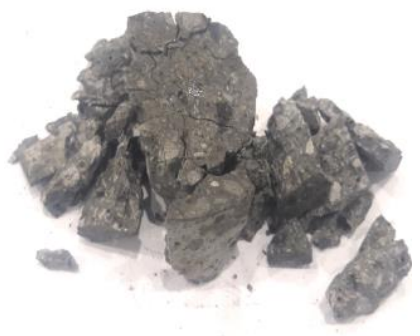

c)

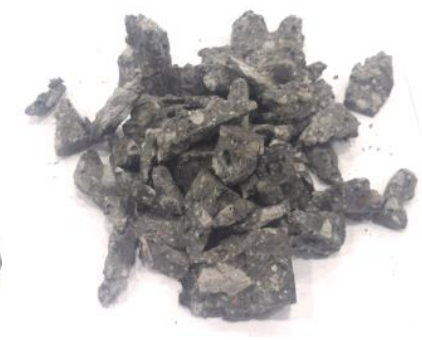

d)

Figure 5: Failure modes of test under different air pressures: a) $P=0.2 \mathrm{MPa}$, b) $P=0.3 \mathrm{MPa}$, c) $P=0.4 \mathrm{MPa}$, d) $P=0.5 \mathrm{MPa}$.

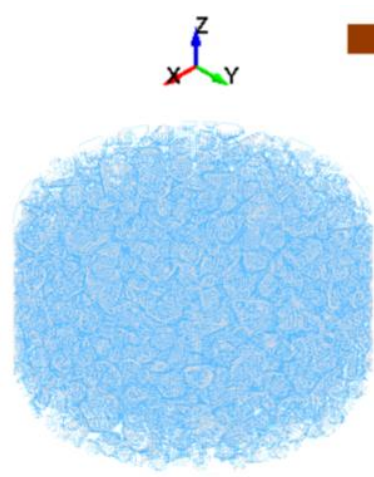

a)

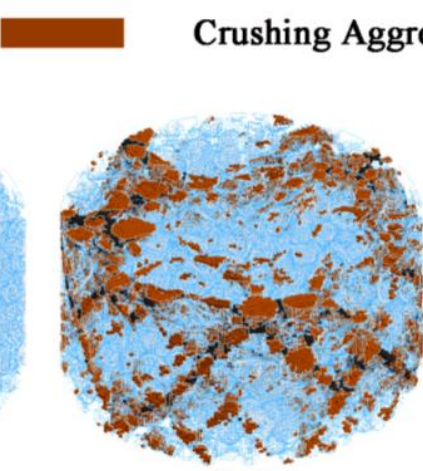

b)

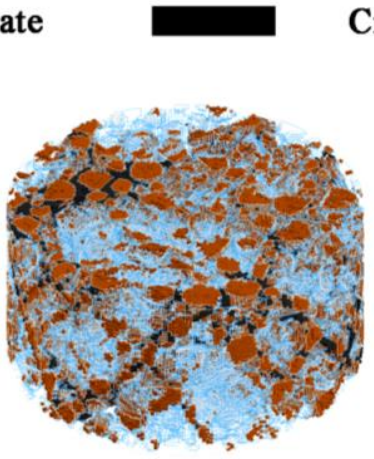

c)
Crushing Mortar

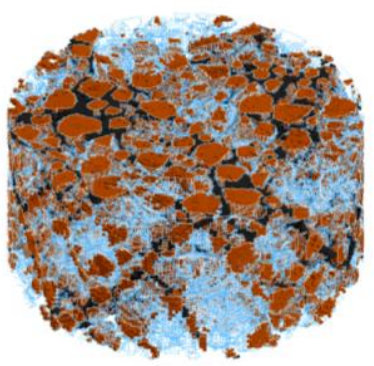

d)

Figure 6: Failure modes of simulation under different air pressures: a) $P=0.2 \mathrm{MPa}$, b) $P=0.3 \mathrm{MPa}$, c) $P=0.4 \mathrm{MPa}$, d) $P=0.5 \mathrm{MPa}$.

The stress-strain curves of the simulation and laboratory tests are shown as Fig. 7. It can be seen that these curves correspond well under different impact pressures. With the increasing of $P$, the peak stress and the envelope area of stress-strain curve increase gradually. 


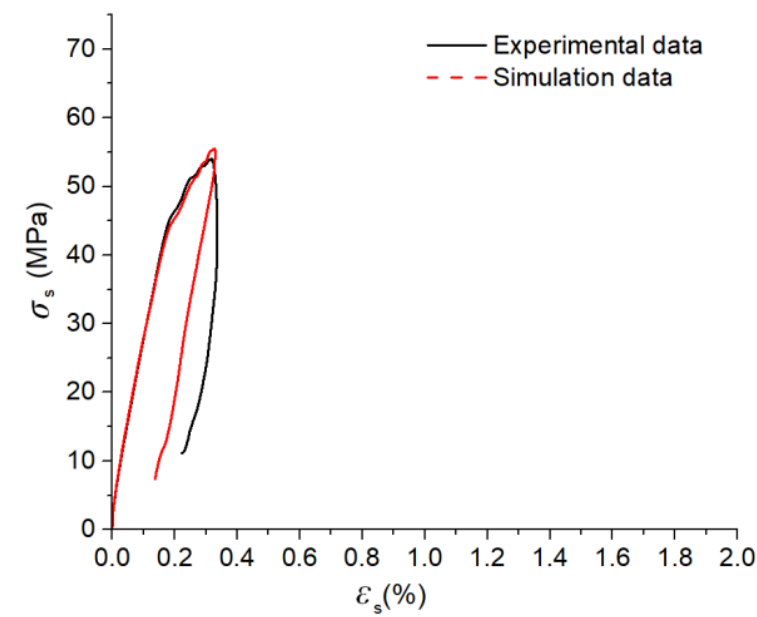

a)

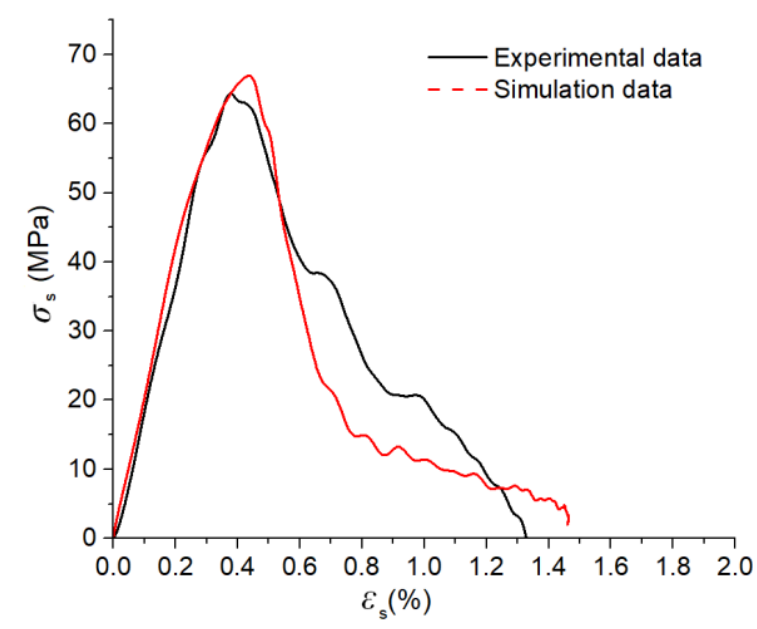

c)

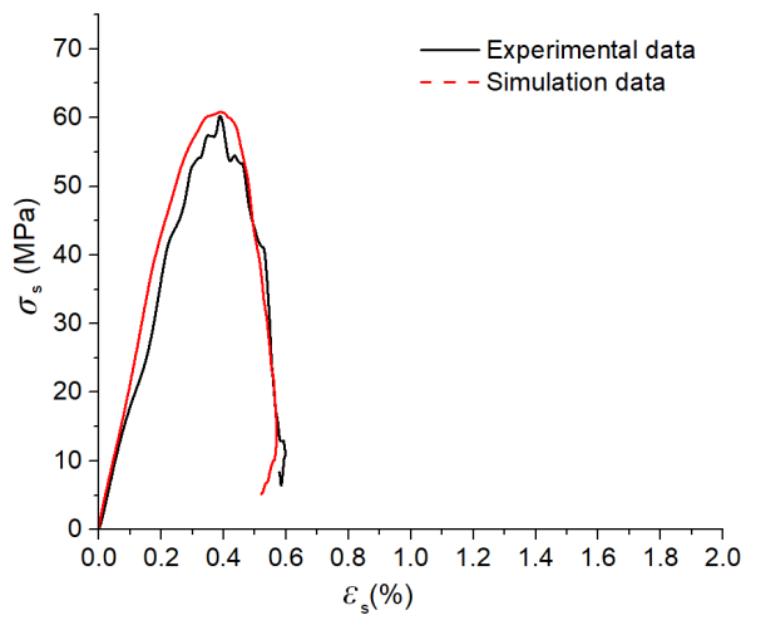

b)

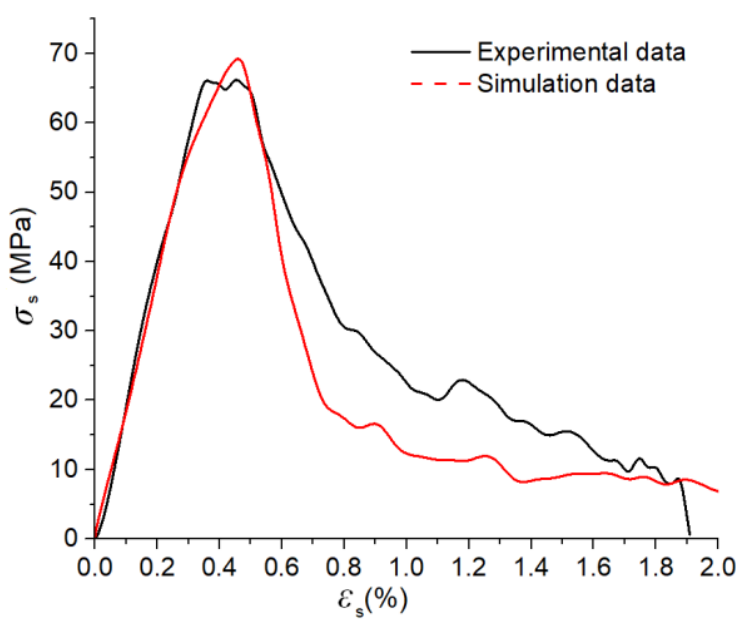

d)

Figure 7: Stress-strain curves between test and simulation results: a) $0.2 \mathrm{MPa}$, b) $0.3 \mathrm{MPa}$, c) $0.4 \mathrm{MPa}$, d) $0.5 \mathrm{MPa}$.

\subsection{Damage evolution process}

The damage evolution process of LWSCC under the air pressure of $0.4 \mathrm{MPa}$ is shown in Fig. 8. According to the development of fracture energy, the damage process can be divided into four stages: elastic-plastic stage, local damage stage, rapid fracture stage and complete fracture stage.

There is no crack appear in stage I. With the increase of stress wave, the internal stress of the specimen increases gradually. In stage II, the stress of LWSCC reaches the peak and then decreases. The crushing energy of the lightweight aggregate begins to increase, while the mortar has not yet broken. In stage III, the stress decreases rapidly since the mortar begins to break and overall failure occurs. At the end of this stage, the crushing of LWSCC is basically completed, and the specimen gradually loses its strength. The element stress remains at a low level and slowly decreased to 0 and the crushing energy does not increase in stage IV.

Several representative times correspond to four points A, B, C and D are shown in Fig. 8. The equivalent strain nephogram and failure mode diagram of LWSCC at representative times are shown in Figs. 9 and 10, respectively. It can be found that before the crack appearing, the lightweight aggregates deform larger. And the stress concentration firstly occurs on them around the specimen, which leads to the generation of micro-cracks. With the further extension and connection of micro-cracks, the specimen was crushed into numerous 
fragments by a large number of main cracks. In addition, the failure of the elements mainly occurs after the peak stress $(t=0.23 \mathrm{~ms})$ at a fast rate.

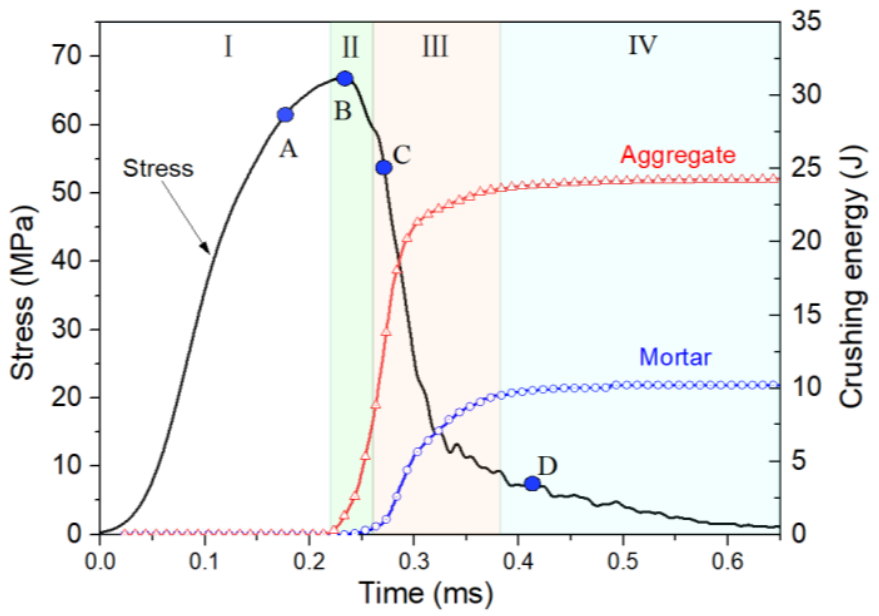

Figure 8: The damage evolution process under the air pressure of $0.4 \mathrm{MPa}$ obtained by simulation.

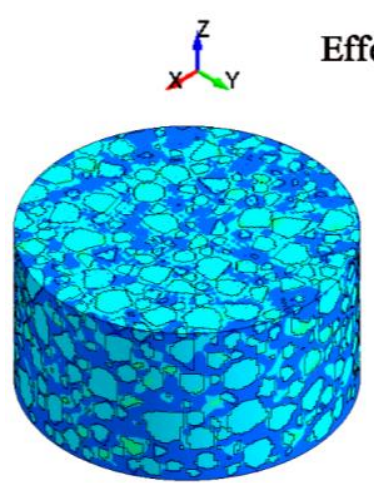

a)

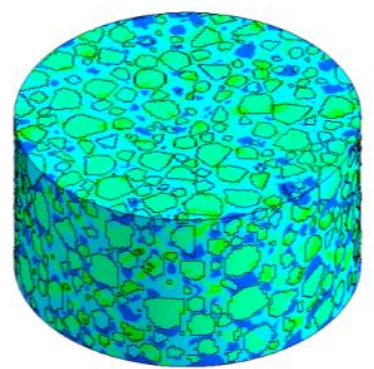

b)

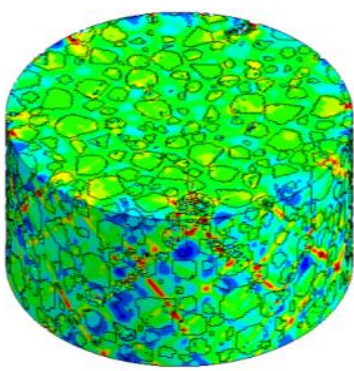

c)

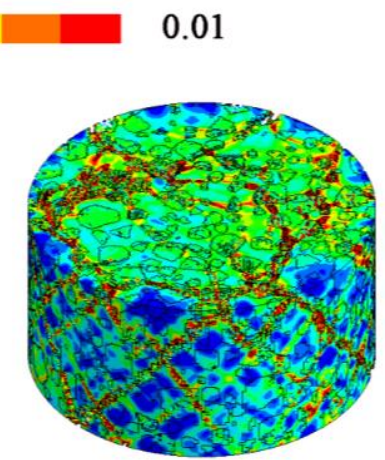

d)

Figure 9: Comparison of effective strain at different times: a) $t=0.18 \mathrm{~ms}$, b) $t=0.23 \mathrm{~ms}$, c) $t=0.27 \mathrm{~ms}$, d) $t=0.41 \mathrm{~ms}$.

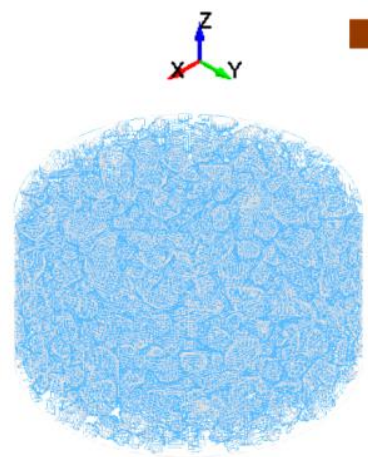

a)

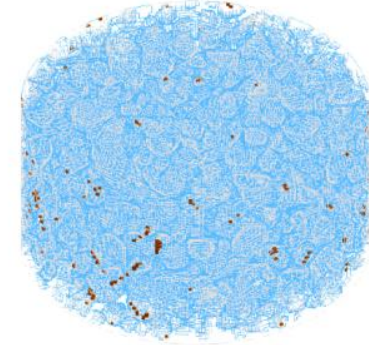

b)

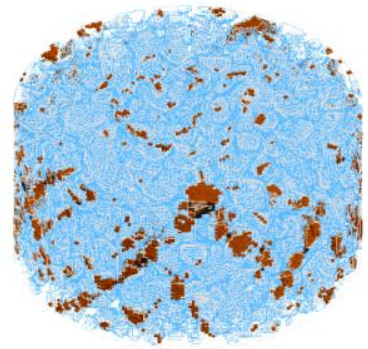

c)

\section{Crushing Mortar}

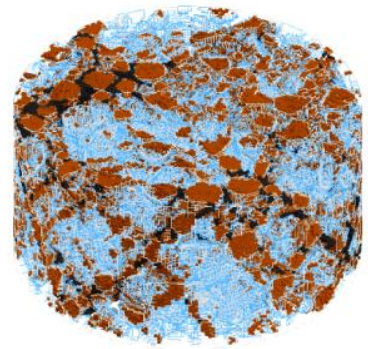

d)

Figure 10: Comparison of failure modes at different times: a) $t=0.18 \mathrm{~ms}, \mathrm{~b}) t=0.23 \mathrm{~ms}$, c) $t=0.27 \mathrm{~ms}$, d) $t=0.41 \mathrm{~ms}$.

\subsection{Energy absorption and dissipation characteristics}

From the perspective of energy, the elastic strain energy is recoverable, while other energy of the system will dissipate, such as plastic strain energy, crushing energy and thermal energy [29]. The proportion of the thermal energy is very small so it was not considered in the 
simulation. The energy dissipation is mainly achieved through plastic deformation, nucleation and expansion of cracks, and the nucleation dissipates much more energy than expansion. In the simulation, the part of energy dissipated through cracking was removed by deleting the failed elements, which was reflected as crushing energy.

The energy evolution process of the LWSCC under impact loading is shown in Fig. 11 a. The total absorbed energy of the specimen is composed of elastic energy, plastic energy and crushing energy. In the beginning, the energy increased with the stress wave enhancing, and accumulated in forms of the elastic and the plastic energy. At $T_{1}$, some elements started to destroy and released the stored energy. After $T_{2}$, the elastic energy that had been stored in the specimen started to recover, so the absorbed energy began to decrease and remained constant after $T_{3}$. The energy recovered from $T_{2}$ to $T_{3}$ was the elastic energy. And the absorbed energy remained was composed of the crushing and the plastic energy. Among them, the plastic energy could drive the fragments to eject after overcoming the friction.

The energy density was proposed to analyse the energy evolution of meso-scale components, the physical meaning of that is the energy per unit mass of a material. The stacking strip diagram of the elastic strain energy density (ESEND), plastic strain energy density (PSEND) and crushing energy density (CEND) of the mortar matrix and the aggregates under different strain rates is shown in Fig. $11 \mathrm{~b}$. The absorbed energy per unit mass of the lightweight aggregate was higher than that of the mortar because of its lower elastic modulus, strong deformation capacity and low density. However, there was an upper limit of strain energy dissipation capacity of the aggregate component, which was about $130 \mathrm{~kJ} / \mathrm{kg}$. The $C E N D$ of the lightweight aggregate was much larger than that of the mortar, which would be more obvious with the strain rates got larger. This result was consistent with the experimental observation, which showed that the higher the strain rate was, the higher the crushing degree of lightweight aggregates would be.

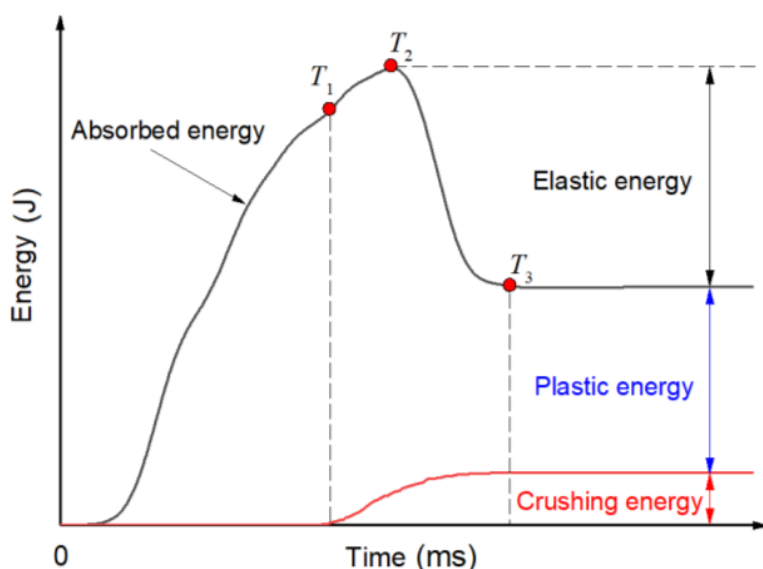

a)

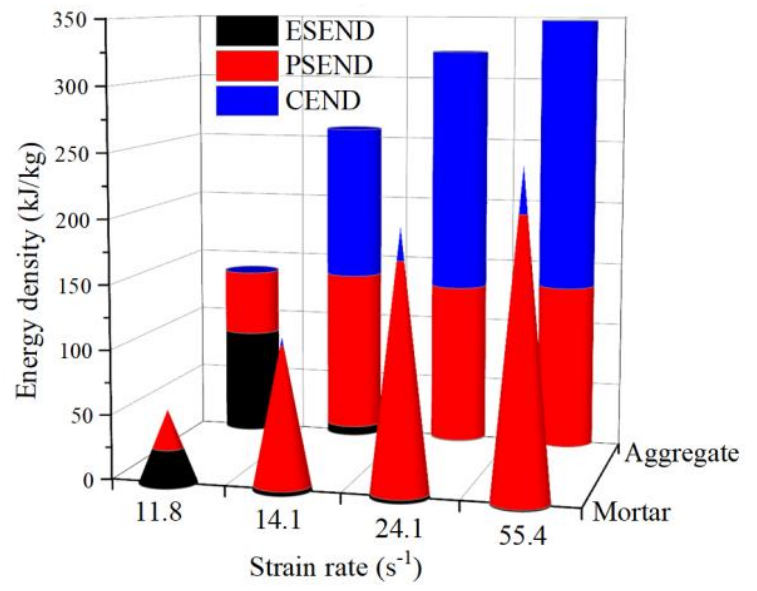

b)

Figure 11: Energy analysis of micro-components: a) energy evolution, b) distribution of absorption energy under different strain rates.

\subsection{Energy absorption characteristics of LWSCC}

The specific energy absorption (SEA) was adopted to measure the energy absorption capacity of concrete materials, which could reduce the effect of the difference among specimens. The physical meaning of $S E A$ was the energy absorbed by unit volume of the specimen. The relationships between the $S E A$ and the strain at different strain rates are shown as Fig. $12 \mathrm{a}$. There was an inflection point in the growth of SEA under the high strain rates. The corresponding strain had no obvious change with the increase of strain rate, while the energy absorption capacity increased, which showed that LWSCC had obvious strain rate effect. 
To better characterize the energy absorption capacity of LWSCC under different strain rates, the energy absorption efficiency $\eta_{\text {abs }}$ can be defined as follows:

$$
\eta_{\mathrm{abs}}=\frac{E_{\mathrm{abs}}}{E_{\mathrm{inp}}}
$$

where, $E_{\mathrm{abs}}, E_{\mathrm{inp}}$ are the absorbed energy and the input energy, respectively. The relationships between $\eta_{\text {abs }}$ and the strain under different strain rates are shown in Fig. 12 b. It can be seen that the energy absorption efficiency increased first and then decreased with the increase of strain rate.

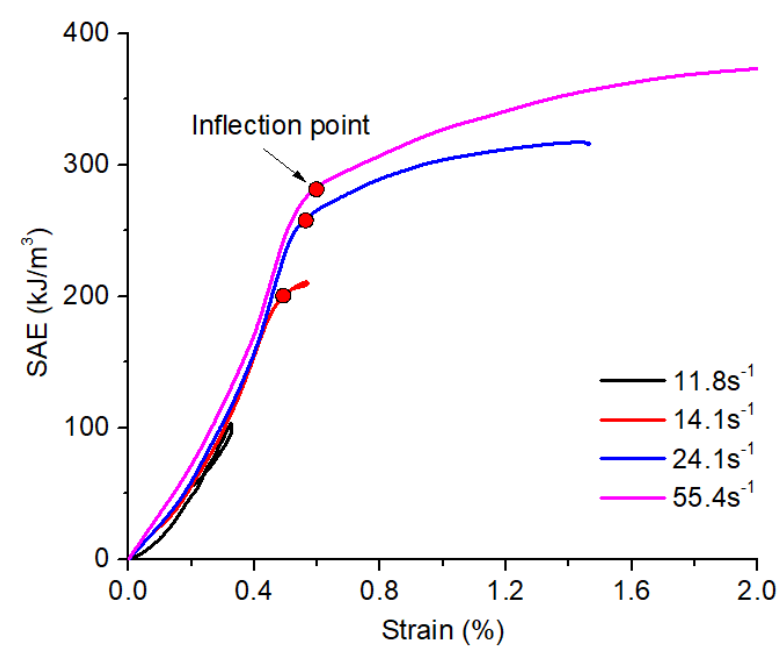

a)

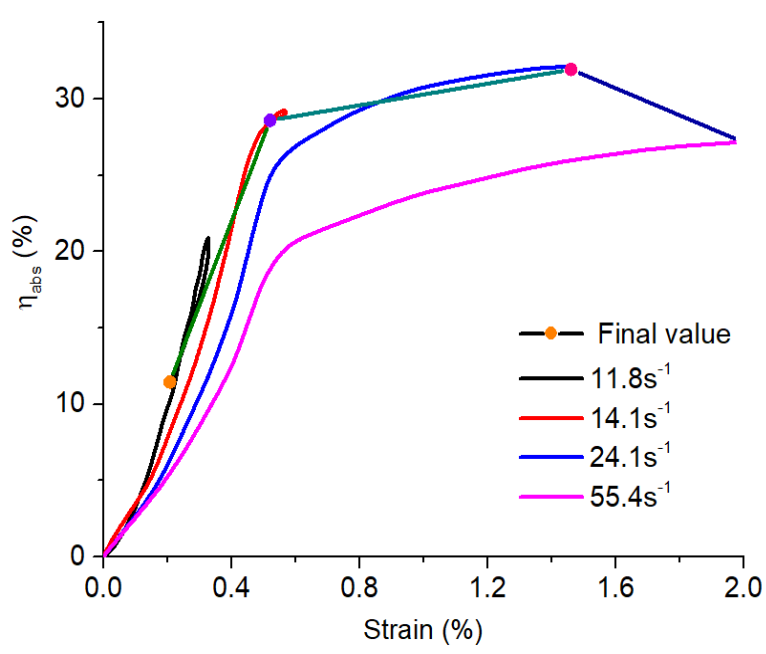

b)

Figure 12: Energy absorption characteristics under different strain rates: a) the specific energy absorption, b) the efficiency of energy absorption.

\section{CONCLUSIONS}

To understand the dynamic characteristics of lightweight shale ceramsite concrete (LWSCC), the 3D random meso-scale model with consideration of random shape and distribution of aggregates was developed. Based on the experimental data, the HJC model parameters of each meso-scale component were determined. Numerical split Hopkinson pressure bar tests under various strain rates were performed. The damage evolution of LWSCC, the energy absorption and dissipation characteristics of the components were analysed. The main conclusions are as follows:

The damage evolution process of LWAC can be divided into four stages: elastic-plastic stage, local damage stage, rapid fracture stage and complete fracture stage. The stress concentration firstly occurs on the aggregates around the specimen, which can cause the generation of micro-cracks. With the further extension and connection of micro-cracks, the specimen can be crushed into numerous fragments by a large number of main cracks.

The energy density of the lightweight aggregate is higher than that of the mortar, especially the crushing energy density. There is an upper limit of strain energy density, which is about $130 \mathrm{~kJ} / \mathrm{kg}$. There is an inflection point in the growth of absorption energy and the corresponding strain of the points have no obvious change with the increase of strain rate. The energy absorption efficiency of LWSCC increases first and then decreases with the increase of strain rate.

The conclusions are of great significance to understand the dynamic performances and damage mechanism of LWAC under impact loading. The mechanical properties of LWAC 
Wang, Zhao, Wu, Yang, Liu: Meso-Scale Simulations of Lightweight Aggregate Concrete ...

under dynamic loads such as penetration and explosion can be further studied by using mesoscale numerical simulation.

\section{ACKNOWLEDGEMENT}

This work was supported by the National Natural Science Foundation of China (51774112), the Fundamental Research Funds for the Universities of Henan Province (NSFRF200202), China.

\section{REFERENCES}

[1] Waldron, C. J.; Cousins, T. E.; Nassar, A. J.; Gomez, J. P. (2005). Demonstration of use of highperformance lightweight concrete in bridge superstructure in Virginia, Journal of Performance of Constructed Facilities, Vol. 19, No. 2, 146-154, doi:10.1061/(asce)0887-3828(2005)19:2(146)

[2] Huang, B.; Xiao, Y. (2020). Compressive impact tests of lightweight concrete with 155-mmdiameter split Hopkinson pressure bar, Cement and Concrete Composites, Vol. 114, Paper 103816, 18 pages, doi:10.1016/j.cemconcomp.2020.103816

[3] Wang, S.; Wu, X.; Yang, J.; Zhu, S. (2020). Acoustic emission characteristics and dynamic damage constitutive relation of shale-ceramsite concrete subjected to loading tests, Journal of Materials in Civil Engineering, Vol. 32, No. 8, Paper 04020202, 9 pages, doi:10.1061/ (ASCE)MT.1943-5533.0003276

[4] Wang, S. R.; Wu, X. G.; Yang, J. H.; Zhao, J. Q.; Kong, F. L. (2020). Mechanical behavior of lightweight concrete structures subjected to 3D coupled static-dynamic loads, Acta Mechanica, Vol. 231, No. 11, 4497-4511, doi:10.1007/s00707-020-02739-y

[5] Yu, R.; van Onna, D. V.; Spiesz, P.; Yu, Q. L.; Brouwers, H. J. H. (2016). Development of ultralightweight fibre reinforced concrete applying expanded waste glass, Journal of Cleaner Production, Vol. 112, No. 1, 690-701, doi:10.1016/j.jclepro.2015.07.082

[6] Wu, Z.; Zhang, J.; Fang, Q.; Yu, H.; Ma, H. (2021). Meso-scopic modelling of concrete material under static and dynamic loadings: A review, Construction and Building Materials, Vol. 278, Paper 122419, 23 pages, doi:10.1016/j.conbuildmat.2021.122419

[7] Zhang, M.; Wu, H. J.; Li, Q. M.; Huang, F. L. (2009). Further investigation on the dynamic compressive strength enhancement of concrete-like materials based on split Hopkinson pressure bar tests. Part I: Experiments, International Journal of Impact Engineering, Vol. 36, No. 12, 1327-1334, doi:10.1016/j.ijimpeng.2009.04.009

[8] Bai, E.-L.; Xu, J.-Y.; Lu, S.; Lin, K.-X.; Zhang, Y.-M. (2018). Comparative study on the dynamic properties of lightweight porous concrete, RSC Advances, Vol. 8, No. 26, 14454-14461, doi:10.1039/C8RA00082D

[9] Dehdezi, P. K.; Erdem, S.; Blankson, M. A. (2015). Physico-mechanical, microstructural and dynamic properties of newly developed artificial fly ash based lightweight aggregate - Rubber concrete composite, Composites Part B: Engineering, Vol. 79, 451-455, doi:10.1016/ j.compositesb.2015.05.005

[10] Hassan, M.; Wille, K. (2017). Experimental impact analysis on ultra-high performance concrete (UHPC) for achieving stress equilibrium (SE) and constant strain rate (CSR) in split Hopkinson pressure bar (SHPB) using pulse shaping technique, Construction and Building Materials, Vol. 144, 747-757, doi:10.1016/j.conbuildmat.2017.03.185

[11] Ren, L.; Yu, X.; He, Y.; Wang, K.; Yao, H. (2020). Numerical investigation of lateral inertia effect in dynamic impact testing of UHPC using a Split-Hopkinson pressure bar, Construction and Building Materials, Vol. 246, Paper 118483, 11 pages, doi: $\underline{10.1016 /}$ j.conbuildmat.2020.118483

[12] Naderi, M.; Kaboudan, A. (2021). Experimental study of the effect of aggregate type on concrete strength and permeability, Journal of Building Engineering, Vol. 37, Paper 101928, 11 pages, doi:10.1016/j.jobe.2020.101928

[13] Xu, W.; Ma, H.; Ji, S.; Chen, H. (2016). Analytical effective elastic properties of particulate composites with soft interfaces around anisotropic particles, Composites Science and Technology, Vol. 129, 10-18, doi:10.1016/j.compscitech.2016.04.011 
[14] Guo, H.; Ooi, E. T.; Saputra, A. A.; Yang, Z.; Natarajan, S.; Ooi, E. H.; Song, C. (2019). A quadtree-polygon-based scaled boundary finite element method for image-based meso-scale fracture modelling in concrete, Engineering Fracture Mechanics, Vol. 211, 420-441, doi:10.1016/j.engfracmech.2019.02.021

[15] Zhang, X.; Yang, Z.-J.; Huang, Y.-J.; Wang, Z.-Y.; Chen, X.-W. (2021). Micro CT image-based simulations of concrete under high strain rate impact using a continuum-discrete coupled model, International Journal of Impact Engineering, Vol. 149, Paper 103775, 21 pages, doi:10.1016/j.ijimpeng.2020.103775

[16] Wang, X. F.; Yang, Z. J.; Yates, J. R.; Jivkov, A. P.; Zhang, C. (2015). Monte Carlo simulations of meso-scale fracture modelling of concrete with random aggregates and pores, Construction and Building Materials, Vol. 75, 35-45, doi:10.1016/j.conbuildmat.2014.09.069

[17] Xia, X.; Chen, F.; Gu, X.; Fang, N.; Zhang, Q. (2021). Interfacial debonding constitutive model and XFEM simulation for mesoscale concrete, Computers \& Structures, Vol. 242, Paper 106373, 16 pages, doi:10.1016/j.compstruc.2020.106373

[18] Nitka, M.; Tejchman, J. (2020). Comparative DEM calculations of fracture process in concrete considering real angular and artificial spherical aggregates, Engineering Fracture Mechanics, Vol. 239, Paper 107309, 19 pages, doi:10.1016/j.engfracmech.2020.107309

[19] Cao, G.; Li, Z.; Xu, Z. (2019). A SPH simulation method for opening flow of fresh concrete considering boundary restraint, Construction and Building Materials, Vol. 198, 379-389, doi:10.1016/j.conbuildmat.2018.11.247

[20] Belytschko, T.; Organ, D.; Gerlach, C. (2000). Element-free galerkin methods for dynamic fracture in concrete, Computer Methods in Applied Mechanics and Engineering, Vol. 187, No. 3 4, 385-399, doi:10.1016/S0045-7825(00)80002-X

[21] Rabczuk, T.; Zi, G.; Bordas, S.; Nguyen-Xuan, H. (2010). A simple and robust three-dimensional cracking-particle method without enrichment, Computer Methods in Applied Mechanics and Engineering, Vol. 199, No. 37-40, 2437-2455, doi:10.1016/j.cma.2010.03.031

[22] Liu, L.; Shen, D.; Chen, H.; Xu, W. (2014). Aggregate shape effect on the diffusivity of mortar: A 3D numerical investigation by random packing models of ellipsoidal particles and of convex polyhedral particles, Computers \& Structures, Vol. 144, 40-51, doi:10.1016/ j.compstruc.2014.07.022

[23] Wu, Z.; Zhang, J.; Yu, H.; Ma, H. (2020). 3D mesoscopic investigation of the specimen aspectratio effect on the compressive behavior of coral aggregate concrete, Composites Part B: Engineering, Vol. 198, Paper 108025, 12 pages, doi:10.1016/j.compositesb.2020.108025

[24] Ouyang, H.; Chen, X. (2020). 3D meso-scale modeling of concrete with a local background grid method, Construction and Building Materials, Vol. 257, Paper 119382, 14 pages, doi:10.1016/j.conbuildmat.2020.119382

[25] Lv, T. H.; Chen, X. W.; Chen, G. (2018). The 3D meso-scale model and numerical tests of split Hopkinson pressure bar of concrete specimen, Construction and Building Materials, Vol. 160, 744-764, doi:10.1016/j.conbuildmat.2017.11.094

[26] Wu, Z.; Zhang, J.; Yu, H.; Ma, H.; Chen, L.; Dong, W.; Huan, Y.; Zhang, Y. (2020). Coupling effect of strain rate and specimen size on the compressive properties of coral aggregate concrete: A 3D meso-scopic study, Composites Part B: Engineering, Vol. 200, Paper 108299, 20 pages, doi:10.1016/j.compositesb.2020.108299

[27] Liu, J.; Ba, M.; He, Z.; Li, Y. (2013). Microstructure and performance of sludge-ceramisite concrete, Construction and Building Materials, Vol. 39, 82-88, doi:10.1016/ j.conbuildmat.2012.05.004

[28] Fan, L.; Zhang, Z.; Yu, Y.; Li, P.; Cosgrove, T. (2017). Effect of elevated curing temperature on ceramsite concrete performance, Construction and Building Materials, Vol. 153, 423-429, doi:10.1016/j.conbuildmat.2017.07.050

[29] Burlion, N.; Gatuingt, F.; Pijaudier-Cabot, G.; Daudeville, L. (2000). Compaction and tensile damage in concrete: constitutive modelling and application to dynamics, Computer Methods in Applied Mechanics and Engineering, Vol. 183, No. 3-4, 291-308, doi:10.1016/S00457825(99)00223-6 